
\title{
25 Research Square \\ Photocatalytic properties of BiFeO 3 powders synthesized by mixture of CTAB and Glycine
}

\section{N. Asefi}

Iran University of Science and Technology

Masood Hasheminiasari ( $\nabla$ mhashemi@iust.ac.ir)

Iran University of Science and Technology https://orcid.org/0000-0002-4314-4982

\section{S. M. Masoudpanah}

Iran University of Science and Technology

\section{Research Article}

Keywords:

Posted Date: April 8th, 2020

DOI: https://doi.org/10.21203/rs.3.rs-21520/v1

License: (1) This work is licensed under a Creative Commons Attribution 4.0 International License. Read Full License 


\section{Abstract}

Highly pure $\mathrm{BiFeO} 3$ (BFO) powders were prepared by solution combustion synthesis method using cetyltrimethylammonium bromide (CTAB) and glycine as fuels at various fuel to oxidant $(\varphi)$ ratios. Microstructural characteristics, morphology, optical properties, and thermal analysis were studied by Xray diffraction (XRD), scanning electron microscopy (SEM), diffuse reflectance spectroscopy (DRS), and differential thermal/thermogravimetry (DTA/TGA), respectively. The combusted powders prepared at different fuel content contained some impurity phases such as Bi24Fe2039 and Bi2Fe409. During the calcination of BFO powders at $600{ }^{\circ} \mathrm{C}$ for 1 hour, nearly pure BFO phase was produced. About $80 \%$ of methylene blue dye was photodegraded by combusted powders at $\varphi=2$ through 90 minutes of visible light irradiation.

\section{Introduction}

Single-phase $\mathrm{BiFeO}_{3}$ (BFO) is a multiferroic material with distorted rhombohedral and perovskite structure exhibiting the R3c space group. Due to its ferroelectric performance at high Curie temperatures up to 830 ${ }^{\circ} \mathrm{C}$ and antiferromagnetic behavior under its Neel temperature of $370{ }^{\circ} \mathrm{C}$, this material can be considered for the applications in non-volatile memory devices, photovoltaic, sensors and spintronics[1-3].

Because of its narrow bandgap in the range of $(2.2-2.8 \mathrm{eV})$ and high chemical stability, BFO has been considered as a visible light photocatalyst to degrade organic pollutants [4]. Many photocatalysts such as $\mathrm{TiO}_{2}, \mathrm{ZnO}, \mathrm{CdS}$, ZnS, etc., have been used for the photodegradation of dyes under ultraviolet (UV) light irradiation [5-10]. However, UV only spans a small portion ( $4 \%)$ of the sunlight spectrum, thus many efforts have been deliberated to develop visible-light catalyst covering a broader spectrum.

Impurity phases such as $\mathrm{Bi}_{2} \mathrm{O}_{3}, \mathrm{Bi}_{2} \mathrm{Fe}_{4} \mathrm{O}_{9}$, and $\mathrm{Bi}_{24} \mathrm{Fe}_{2} \mathrm{O}_{39}$ appear during the synthesis of $\mathrm{BFO}$ due to its phase formation's kinetics. Therefore, many researchers developed various synthesis routes to remove these secondary phases, namely through hydrothermal synthesis [11], [12], polymer assisted hydrothermal [13], sol-gel synthesis [14], co-precipitation [15-17], aerosol-spraying, electrospinning [18], solvothermal route[19], and solution combustion method [20].

Developing simple, environmentally safe, and energy-efficient methods are of great interest to synthesize a pure BFO powder. Solution combustion synthesis (SCS) is a simple, relatively cheap, and fast chemical process to produce various nanomaterials [21]. A self-propagating exothermic reaction takes place between the mixture of metal nitrates and different organic fuels (e.g., glycine, citric acid, urea, etc.), releasing an enormous amount of gaseous products [20].

Among organic fuels, glycine is an amino acid that facilitates the formation of metal ion complex in the solution owing to its carboxylic acid and amino groups at opposite ends of the molecule [22]. BFO has been synthesized by glycine fuel thru microwave-assisted solution combustion with some portion of impurity phases such as $\mathrm{Bi}_{2} \mathrm{Fe}_{4} \mathrm{O}_{9}$ and $\mathrm{Bi}_{24} \mathrm{Fe}_{2} \mathrm{O}_{39}$ [23]. Likewise, Cetyltrimethylammonium bromide 
(CTAB) is a cationic surfactant with high decomposition temperature that is extensively used to control particle shapes, size, and microstructure via minimizing the precursor's surface tension [24]. Nevertheless, combining different fuels might be more effectual than that of individual fuels via improved control over the reaction temperature, the type, and the amount of gaseous products released. Therefore, in this project, glycine and CTAB were mixed in the uni-molar ratio to synthesize nearly pure and single-phase BFO.

\section{Experimental Procedure}

\section{Synthesis Route}

Analytical grades $\mathrm{Fe}\left(\mathrm{NO}_{3}\right)_{3} \cdot 9 \mathrm{H}_{2} \mathrm{O}, \mathrm{Bi}\left(\mathrm{NO}_{3}\right)_{2} \cdot 5 \mathrm{H}_{2} \mathrm{O}, \mathrm{CTAB}\left[\left(\mathrm{C}_{16} \mathrm{H}_{33}\right) \mathrm{N}\left(\mathrm{CH}_{3}\right)_{3}\right] \mathrm{Br}(>99 \%)$, glycine $\left(\mathrm{C}_{2} \mathrm{H}_{5} \mathrm{NO}_{2}\right)$, were purchased from Merk Co. without any further purification. Whereby $\mathrm{HNO}_{3}(68 \mathrm{wt} \%)$ was added to dissolve bismuth nitrate.

The required amount of $\mathrm{Bi}\left(\mathrm{NO}_{3}\right) \cdot 5 \mathrm{H}_{2} \mathrm{O}$ and $\mathrm{Fe}\left(\mathrm{NO}_{3}\right) \cdot 9 \mathrm{H}_{2} \mathrm{O}$, cetyltrimethylammonium bromide $\left(\left[\left(\mathrm{C}_{16} \mathrm{H}_{33}\right) \mathrm{N}\left(\mathrm{CH}_{3}\right)_{3}\right] \mathrm{Br}\right)$, and glycine $\left(\mathrm{C}_{2} \mathrm{H}_{5} \mathrm{NO}_{2}\right)$ were prepared by dissolving $15 \mathrm{~mL}$ of $3 \mathrm{~mol} \mathrm{~L}^{-1}$ of $\mathrm{HNO}_{3}$ in various fuel to oxidant ratios of $(\varphi=0.5,0.75,1$ and 2$) . \mathrm{H}_{2} \mathrm{O}, \mathrm{CO}_{2}, \mathrm{Br}_{2}$, and $\mathrm{N}_{2}$ are assumed to be the gaseous products of combustion reaction where the type of gaseous products and adiabatic temperature are controlled by the fuel to oxidant ratio $(\varphi)$.

$\mathrm{Bi}\left(\mathrm{NO}_{3}\right)_{3}+\mathrm{Fe}\left(\mathrm{NO}_{3}\right)_{3}+\left(\varphi \mathrm{C}_{19} \mathrm{H}_{36} \mathrm{NBr}+\varphi \mathrm{C}_{2} \mathrm{H}_{5} \mathrm{NO}_{2}\right)+(\varphi-1) \mathrm{O}_{2} \mathrm{BiFeO}_{3}+\varphi \mathrm{CO}_{2}+\varphi \mathrm{H}_{2} \mathrm{O}+(3+\varphi) \mathrm{N}_{2}+\varphi \mathrm{Br}_{2}$

IR spectra in the range of $\left(400-4000 \mathrm{~cm}^{-1}\right)$ were recorded by 8500 S SHIMADZU spectrophotometer. Differential thermal (DTA) and thermogravimetry analysis (TGA) were used to study the combustion behavior in the air with a heating rate of $5^{\circ} \mathrm{C} / \mathrm{min}$ on an STA Ba"HR 503 instrument.

Microstructure and phase evolution were examined by X-ray diffraction (PANalytical X'pert, CuKa = $1.54060 \mathrm{~A}^{\circ}$ ). Crystallite sizes were also calculated using the raw data from XRD by the Williamson-Hall method.

Field emission scanning electron microscopy (FE-SEM) was acquired to characterize the morphology of the as-combusted powders by TESCAN Vega II.

UV-Vis diffuse reflectance spectrum (DRS) was acquired to measure the bandgap and visible light absorption of the powders by a Shimadzu UV-Vis 52550 spectrophotometer in the wavelength range of $(300-800 \mathrm{~nm})$.

\section{Photocatalytic Performance}

Visible light irradiation (two $100 \mathrm{~W}$ Xenon lamps with a cutoff ultraviolet filter) was utilized to photodegrade the methylene blue (MB) dye in the presence of as-combusted BFO powders. $100 \mathrm{mg}$ of 
BFO catalyst was dispersed in $100 \mathrm{~mL}$ of methylene blue $(15 \mathrm{mg} / \mathrm{L})$ in the presence of $0.1 \mathrm{~mL} \mathrm{H}_{2} \mathrm{O}_{2}$ (30\%) stirred for 60 minutes in dark to obtain the adsorption/desorption equilibrium. Furthermore, the $\mathrm{pH}$ of the solution was adjusted by $\mathrm{HCl}(37 \mathrm{wt} \%)$. BFO powders were separated by centrifugation at 6000 rpm for 10 min followed by the MB concentration monitoring on PG Instruments Ltd T80-UV/Vis spectrophotometer.

\section{Results And Discussion}

Fig. 1 illustrates the thermal analysis of dried gel produced by a mixture of glycine and CTAB fuels at $\varphi=$ 1. A slight drop ( 9\%) in the gel's mass is possibly due to the evaporation of absorbed water, while a sharp decline at about $178{ }^{\circ} \mathrm{C}$ can be triggered by the exothermic reaction between metal nitrates with glycine and CTAB fuels. This enormous drop $(\sim 70 \%)$ in the mass of gel is because of a combustion reaction that released a large amount of gaseous products such as $\mathrm{CO}_{2}, \mathrm{H}_{2} \mathrm{O}, \mathrm{N}_{2}, \mathrm{Br}_{2}$, etc.

Based on previous findings [25-26], Glycine has a lower decomposition temperature compared to CTAB with fast combustion reaction rate showing sharp weight loss in the gel. Similarly, when the mixture of glycine and CTAB are used as fuels, huge weight loss seems to be dominated by the presence of glycine rather than CTAB. Furthermore, smaller exothermic peak at $285^{\circ} \mathrm{C}$ with a gradual weight loss might be attributed to the slow oxidation reaction of residual organics remained in the gel [27].

FTIR spectra of dried gel and as-combusted powders prepared by the mixture of glycine and CTAB fuels at $\varphi=1$ are illustrated in Fig.2. The broad vibrational stretching modes at the range of $3200-3700 \mathrm{~cm}^{-1}$ correspond to the absorption of hydroxyl groups of water molecules that are omitted in the as combusted BFO powders [28]. Stretching vibration of $\mathrm{C}-\mathrm{H}$ bonds in CTAB molecules can lead to the formation of bands at 2920 and $2850 \mathrm{~cm}^{-1}$ [29]. The vibrational band at $1350 \mathrm{~cm}^{-1}$ is due to the attachment of $\mathrm{CO}_{2}$ groups to the cations [28]. The adsorption bands at $1650 \mathrm{~cm}^{-1}, 1360 \mathrm{~cm}^{-1}, 902 \mathrm{~cm}^{-1}, 802 \mathrm{~cm}^{-1}$, and 730 $\mathrm{cm}^{-1}$ confirm the formation of $\mathrm{NO}^{-3}$ connected to the CTAB and glycine molecules in the dried gel [30]. Stretching bands at $1757 \mathrm{~cm}^{-1}$ and $1556 \mathrm{~cm}^{-1}$ resemble the existence of $100^{-}$groups formed through the oxidation of CTAB molecules [31]. Peaks at $1105 \mathrm{~cm}^{-1}$ and $1020 \mathrm{~cm}^{-1}$ confirm the presence of $\mathrm{NH}_{2}$ groups. Carboxylate groups can chelate cations leading to the absorption band at $586 \mathrm{~cm}^{-1}$ corresponded to metal-oxygen bonds [32]. Strong peaks at $557 \mathrm{~cm}^{-1}$ and $465 \mathrm{~cm}^{-1}$ of combusted powder can be assigned to the vibrational bending and stretching of $\mathrm{Fe}-\mathrm{O}$ in the octahedral $\mathrm{FeO}_{6}$ groups in perovskite structure [33].

XRD patterns of conventionally combusted BFO powders at the various $\varphi$ values are depicted in Fig. 3 . The as combusted powders at $\varphi=0.5$ and $\varphi=0.75$ are semi-amorphous, due to their incomplete combustion reaction and low adiabatic combustion temperature. $\mathrm{Bi}_{2} \mathrm{Fe}_{4} \mathrm{O}_{9}$ (JCDPS Card No. 00-0200836) impurity phase is presented at $\varphi$ values of 0.5 and 0.75 . However, maximum adiabatic temperature occurs at $\varphi=1$ leading to a well crystalline pattern. $\mathrm{Bi}_{24} \mathrm{Fe}_{2} \mathrm{O}_{39}$ (JCDPS Card No. 00-042-0201) was the only impurity phase formed at the $\varphi$ values of 1 and 2 . 
$\mathrm{Bi}_{2} \mathrm{O}_{3}$ and $\mathrm{Fe}_{2} \mathrm{O}_{3}$, as the transitional phases, can take part in the solid reaction of $\left(\mathrm{Bi}_{2} \mathrm{O}_{3}+\mathrm{Fe}_{2} \mathrm{O}_{3} \rightarrow 2\right.$ $\mathrm{BiFeO}_{3}$ ) to produce the $\mathrm{BiFeO}_{3}$ phase. Nevertheless, the formation of impurity phases such as $\mathrm{Bi}_{2} \mathrm{Fe}_{4} \mathrm{O}_{9}$ and $\mathrm{Bi}_{24} \mathrm{Fe}_{2} \mathrm{O}_{39}$ can be ascribed to the insufficiency of $\mathrm{Bi}_{2} \mathrm{O}_{3}$ and $\mathrm{Fe}_{2} \mathrm{O}_{3}$ phases initiated by the phase segregation [34]:

$\mathrm{Bi}_{2} \mathrm{O}_{3}+2 \mathrm{Fe}_{2} \mathrm{O}_{3} \rightarrow \mathrm{Bi}_{2} \mathrm{Fe}_{4} \mathrm{O}_{9}$

$12 \mathrm{Bi}_{2} \mathrm{O}_{3}+\mathrm{Fe}_{2} \mathrm{O}_{3} \rightarrow \mathrm{Bi}_{24} \mathrm{Fe}_{2} \mathrm{O}_{39}$

Inferior crystallinity of as-combusted powders due to their lower combustion temperatures can be improved by further calcination at higher temperatures (Fig. 4). Impurity phases were mostly eliminated by one-hour calcination at $600{ }^{\circ} \mathrm{C}$ due to the reaction of the residual $\mathrm{Bi}_{2} \mathrm{O}_{3}$ and $\mathrm{Fe}_{2} \mathrm{O}_{3}$ phases.

$\mathrm{Bi}_{2} \mathrm{O}_{3}+\mathrm{Bi}_{2} \mathrm{Fe}_{4} \mathrm{O}_{9} \rightarrow 4 \mathrm{BiFeO}_{3}$

$11 \mathrm{Fe}_{2} \mathrm{O}_{3}+\mathrm{Bi}_{24} \mathrm{Fe}_{2} \mathrm{O}_{39} \rightarrow 24 \mathrm{BiFeO}_{3}$

SEM micrographs of BFO powders synthesized at different $\varphi$ values are illustrated in Fig. 5. As combusted powders display a bulky microstructure where the particle sizes are reduced from 37 to $18 \mathrm{~nm}$ with the increase in fuel content presented in Table 1, as calculated from XRD data using the WilliamsonHall technique. Particle size mainly depends on the combustion temperature and reaction rate, where the combustion rate would influence the number of nucleation sites and higher combustion temperature enhances the particle growth [35]. When the fuel content is increased, the higher amount of generated heat is consumed by the combustion gases and hence reduces the adiabatic temperature. This decline in the adiabatic temperature resulted in particle size refinement. However, as calcined powders show the particle size enlargement due to the increase in temperature, as depicted in Fig. 5 (d-f).

Another proposed reason behind this particle size refinement at higher CTAB/glycine content, as illustrated schematically in Fig. 6, could be due to the interaction of CTAB micelles with the cationic head inside the solution precursor, separated a large amount of the cationic ends apart and produced smaller BFO nanoparticles when the CTAB amount was maximized. Fig. 7a displays diffuse reflectance spectra of the as combusted BFO powders. The amount of visible light absorption mainly depends on the crystallinity, strain, particle size, impurity phases, and etc. The crystal field and metal-metal transitions highly affect the absorption spectra [36]. The increase in light absorption at higher fuel content $(\varphi=2)$, is possibly due to the decrease in the amount of impurity phase $\mathrm{Bi}_{24} \mathrm{Fe}_{2} \mathrm{O}_{39}$. However, powders synthesized at fuel content of $(\varphi=0.75)$ significantly absorbed a higher amount of visible light probably due to the formation of dissimilar impurity phase of $\mathrm{Bi}_{2} \mathrm{Fe}_{4} \mathrm{O}_{9}$, as previously discussed in XRD data. Bandgap energy of the combusted powders was measured by the Tauc's plot ((ahu $)^{2}$ vs. hu), as shown in Fig. 7b and summarized in Table 1. The bandgap energies of the combusted BFO powders are in the range of 1.85-1.96 eV in a good agreement with the bandgap of powders and thin films reported in the literature [36]. At higher fuel contents, the decrease in bandgap energy is mainly due to the particle size refinement 
while the increase in the bandgap energy at $\varphi=2$ could be owed to the presence of the impurity phase $\mathrm{Bi}_{24} \mathrm{Fe}_{2} \mathrm{O}_{39}$.

The relative concentrations $\left(\mathrm{C} / \mathrm{C}_{0}\right)$ of $\mathrm{MB}$, as an organic pollutant, versus visible light irradiation is illustrated in Fig. 8. The MB is photodegraded by about $80 \%$ during 90 minutes of visible light illumination for combusted powders at $\varphi$ values of 2 and 0.75 . However, the degradation rate is slightly higher for the combusted powders synthesized at $\varphi=2$. Based on our previous findings [23-24], the as combusted powders synthesized by pure glycine or pure CTAB, only showed the photodegradation of MB at about 50 and 30 percents, respectively. Therefore, by mixing the glycine and CTAB fuels, the photodegradation of $\mathrm{MB}$ is profoundly enhanced possibly due to the particle size refinement and higher crystallinity with less amount of impurity phases being present. The oxidation and reduction of MB dye molecule to $\mathrm{CO}_{2}$ and $\mathrm{H}_{2} \mathrm{O}$ species mainly depends on the presence of active species such as $\mathrm{O}^{-2}, \mathrm{OH}$ radicals [37]. The photogenerated electrons and holes during the light absorption of powders would react with the oxygen and water molecules to produce the active species. Thus, the optical properties of combusted powders such as bandgap energy, absorption coefficient, and band edge position play an important role in photocatalytic performance [38].

\section{Conclusions}

High purity BFO powders were synthesized via solution combustion synthesis by the mixture of glycine and CTAB as fuels at different fuel contents. The amount of the impurity phase was reduced by increasing fuel content from 0.5 to 2 . $\mathrm{Bi}_{2} \mathrm{Fe}_{4} \mathrm{O}_{9}$ impurity phase was present at $\varphi$ values of 0.5 and 0.75 . However, at higher fuel ratios ( $\varphi$ values of 1 and 2 ) the impurity phase was transformed into the $\mathrm{Bi}_{24} \mathrm{Fe}_{2} \mathrm{O}_{39}$ phase.

The combusted powders at $\varphi$ values of 2 and 0.75 showed the highest MB photodegradation of about 80 $\%$ under 90 minutes of visible light illumination mainly due to the particle size refinement, higher visible light absorption, and less amount of impurities. Furthermore, the photodegradation rate of combusted powders synthesized at $\varphi=2$ was somewhat enhanced.

\section{References}

[1] H. Shokrollahi, "Magnetic, electrical and structural characterization of BiFeO3 nanoparticles synthesized by co-precipitation," Powder Technol., vol. 235, pp. 953-958, 2013.

[2] P. R. Vanga, R. V Mangalaraja, and M. Ashok, "Structural, magnetic and photocatalytic properties of La and alkaline co-doped BiFeO3 nanoparticles," Mater. Sci. Semicond. Process., vol. 40, pp. 796-802, 2015.

[3] S. Chen et al., "Hand-Fabricated CNt/AgNps electrodes using Wax-on-plastic platforms for electroImmunosensing Application," Sci. Rep., vol. 9, no. 1, p. 6131, 2019. 
[4] R. Guo, L. Fang, W. Dong, F. Zheng, and M. Shen, "Enhanced photocatalytic activity and ferromagnetism in Gd doped BiFeO3 nanoparticles," J. Phys. Chem. C, vol. 114, no. 49, pp. 21390-21396, 2010.

[5] Y. Chen, Y. Tang, S. Luo, C. Liu, and Y. Li, "TiO2 nanotube arrays co-loaded with Au nanoparticles and reduced graphene oxide: Facile synthesis and promising photocatalytic application," J. Alloys Compd., vol. 578, pp. 242-248, 2013.

[6] Y. Zhang, W. Cui, W. An, L. Liu, Y. Liang, and Y. Zhu, "Combination of photoelectrocatalysis and adsorption for removal of bisphenol A over TiO2-graphene hydrogel with 3D network structure," Appl. Catal. B Environ., vol. 221, pp. 36-46, 2018.

[7] A. Nag, S. Sapra, S. Chakraborty, S. Basu, and D. D. Sarma, "Synthesis of CdSe nanocrystals in a noncoordinating solvent: effect of reaction temperature on size and optical properties," J. Nanosci. Nanotechnol., vol. 7, no. 6, pp. 1965-1968, 2007.

[8] K. Rajeshwar et al., "Heterogeneous photocatalytic treatment of organic dyes in air and aqueous media," J. Photochem. Photobiol. C Photochem. Rev., vol. 9, no. 4, pp. 171-192, 2008.

[9] J.-M. Herrmann, "Heterogeneous photocatalysis: fundamentals and applications to the removal of various types of aqueous pollutants," Catal. today, vol. 53, no. 1, pp. 115-129, 1999.

[10] Y. Fu and X. Wang, "Magnetically separable ZnFe204-graphene catalyst and its high photocatalytic performance under visible light irradiation," Ind. Eng. Chem. Res., vol. 50, no. 12, pp. 7210-7218, 2011.

[11] T. Gao et al., "Shape-controlled preparation of bismuth ferrite by hydrothermal method and their visible-light degradation properties," J. Alloys Compd., vol. 648, pp. 564-570, 2015.

[12] X. Wang et al., "PVP assisted hydrothermal fabrication and morphology-controllable fabrication of BiFeO3 uniform nanostructures with enhanced photocatalytic activities," J. Alloys Compd., vol. 677, pp. 288-293, 2016.

[13] Y. Wang et al., "Low temperature polymer assisted hydrothermal synthesis of bismuth ferrite nanoparticles," Ceram. Int., vol. 34, no. 6, pp. 1569-1571, 2008.

[14] T. Gao et al., "Synthesis of BiFeO3 nanoparticles for the visible-light induced photocatalytic property," Mater. Res. Bull., vol. 59, pp. 6-12, 2014.

[15] H. Ke et al., "Factors controlling pure-phase multiferroic BiFeO3 powders synthesized by chemical coprecipitation," J. Alloys Compd., vol. 509, no. 5, pp. 2192-2197, 2011.

[16] H. Y. Bo, G. Q. Tan, H. Y. Miao, and A. Xia, "Co-precipitation synthesis of BiFeO3 powders," in Advanced Materials Research, 2010, vol. 105, pp. 286-288. 
[17] Z. Liu, Y. Qi, and C. Lu, "High efficient ultraviolet photocatalytic activity of BiFeO 3 nanoparticles synthesized by a chemical coprecipitation process," J. Mater. Sci. Mater. Electron., vol. 21, no. 4, pp. 380$384,2010$.

[18] W. Wang et al., "Electrospinning of magnetical bismuth ferrite nanofibers with photocatalytic activity," Ceram. Int., vol. 39, no. 4, pp. 3511-3518, 2013.

[19] Y. Huo, Y. Jin, and Y. Zhang, "Citric acid assisted solvothermal synthesis of BiFeO3 microspheres with high visible-light photocatalytic activity," J. Mol. Catal. A Chem., vol. 331, no. 1-2, pp. 15-20, 2010.

[20] J. Yang, X. Li, J. Zhou, Y. Tang, Y. Zhang, and Y. Li, "Factors controlling pure-phase magnetic BiFeO3 powders synthesized by solution combustion synthesis," J. Alloys Compd., vol. 509, no. 37, pp. 92719277, 2011.

[21] S. T. Aruna and A. S. Mukasyan, "Combustion synthesis and nanomaterials," Curr. Opin. solid state Mater. Sci., vol. 12, no. 3-4, pp. 44-50, 2008.

[22] A. Motevalian and S. Salem, "Effect of glycine-starch mixing ratio on the structural characteristics of MgAl204 nano-particles synthesized by sol-gel combustion," Particuology, vol. 24, pp. 108-112, 2016.

[23] N. Asefi, S. M. Masoudpanah, and M. Hasheminiasari, "Microwave-assisted solution combustion synthesis of BiFeO 3 powders," J. Sol-Gel Sci. Technol., pp. 1-9, 2018.

[24] N. Asefi, M. Hasheminiasari, and S. M. Masoudpanah, "Solution Combustion Synthesis of BiFeO 3 Powders Using CTAB as Fuel,” J. Electron. Mater., pp. 1-7, 2018.

[25] J. Huang, G. Tan, W. Yang, L. Zhang, H. Ren, and A. Xia, "Microwave hydrothermal synthesis of BiFeO 3: impact of different surfactants on the morphology and photocatalytic properties," Mater. Sci. Semicond. Process., vol. 25, pp. 84-88, 2014.

[26] U. A. Joshi, J. S. Jang, P. H. Borse, and J. S. Lee, "Microwave synthesis of single-crystalline perovskite Bi Fe 03 nanocubes for photoelectrode and photocatalytic applications," Appl. Phys. Lett., vol. 92, no. 24, p. 242106, 2008.

[27] M. Radpour, S. M. Masoudpanah, and S. Alamolhoda, "Microwave-assisted solution combustion synthesis of Fe304 powders," Ceram. Int., vol. 43, no. 17, pp. 14756-14762, 2017.

[28] G. Socrates, "Infrared and Raman Characteristic Group Frequencies, 3rd edn., J." Wiley \& Sons Ltd., England, 2001.

[29] S. F. N. Hamedani, S. M. Masoudpanah, M. S. Bafghi, and N. A. Baloochi, "Solution combustion synthesis of CoFe 204 powders using mixture of CTAB and glycine fuels," J. Sol-Gel Sci. Technol., vol. 86, no. 3, pp. 743-750, 2018. 
[30] P. Naderi, S. M. Masoudpanah, and S. Alamolhoda, "Magnetic properties of Li0. 5Fe2. 504 nanoparticles synthesized by solution combustion method," Appl. Phys. A, vol. 123, no. 11, p. 702, 2017.

[31] S. Shabani, S. M. Mirkazemi, S. M. Masoudpanah, and P. T. D. Abadi, "Synthesis and characterization of pure single phase BiFeO 3 nanoparticles by the glyoxylate precursor method," J. Supercond. Nov. Magn., vol. 27, no. 12, pp. 2795-2801, 2014.

[32] J. L. Ortiz-Quiñonez et al., "Easy synthesis of high-purity BiFeO3 nanoparticles: new insights derived from the structural, optical, and magnetic characterization," Inorg. Chem., vol. 52, no. 18, pp. 1030610317, 2013.

[33] S. M. Masoudpanah, S. M. Mirkazemi, R. Bagheriyeh, F. Jabbari, and F. Bayat, "Structural, magnetic and photocatalytic characterization of $\mathrm{Bi} 1-\mathrm{x} \mathrm{La} x \mathrm{FeO} 3$ nanoparticles synthesized by thermal decomposition method," Bull. Mater. Sci., vol. 40, no. 1, pp. 93-100, 2017.

[34] K. Feng, L.-C. Wang, J. Lu, Y. Wu, and B.-G. Shen, “Experimentally determining the intrinsic center point of $\mathrm{Bi} 203-\mathrm{Fe} 203$ phase diagram for growing pure BiFeO 3 crystals," CrystEngComm, vol. 15, no. 24, pp. 4900-4904, 2013.

[35] F. Deganello and A. K. Tyagi, "Solution combustion synthesis, energy and environment: Best parameters for better materials," Prog. Cryst. Growth Charact. Mater., vol. 64, no. 2, pp. 23-61, 2018.

[36] S.-M. Lam, J.-C. Sin, and A. R. Mohamed, "A newly emerging visible light-responsive BiFe03 perovskite for photocatalytic applications: A mini review," Mater. Res. Bull., vol. 90, pp. 15-30, 2017.

[37] K. Prashanthi, G. Thakur, and T. Thundat, "Surface enhanced strong visible photoluminescence from one-dimensional multiferroic BiFeO3 nanostructures," Surf. Sci., vol. 606, no. 19-20, pp. L83-L86, 2012.

[38] T. Soltani and M. H. Entezari, "Photolysis and photocatalysis of methylene blue by ferrite bismuth nanoparticles under sunlight irradiation," J. Mol. Catal. A Chem., vol. 377, pp. 197-203, 2013.

\section{Table}

Table 1 Crystallite size ( $\left(\mathrm{D}_{\mathrm{XRD}}\right)$ of $\mathrm{BiFeO}_{3}$ phase, and bandgap energy (Eg) as a function of fuel type.

\begin{tabular}{|c|c|c|}
\hline As-combusted & $\mathrm{D}_{\mathrm{XRD}}(\mathrm{nm})$ & $\mathrm{Eg}(\mathrm{eV})$ \\
\hline 0.5 & $\mathbf{3 7}$ & 1.96 \\
\hline 0.75 & $\mathbf{2 8}$ & 1.85 \\
\hline 1 & $\mathbf{2 1}$ & 1.96 \\
\hline 2 & $\mathbf{1 8}$ & 1.96 \\
\hline
\end{tabular}

\section{Figures}




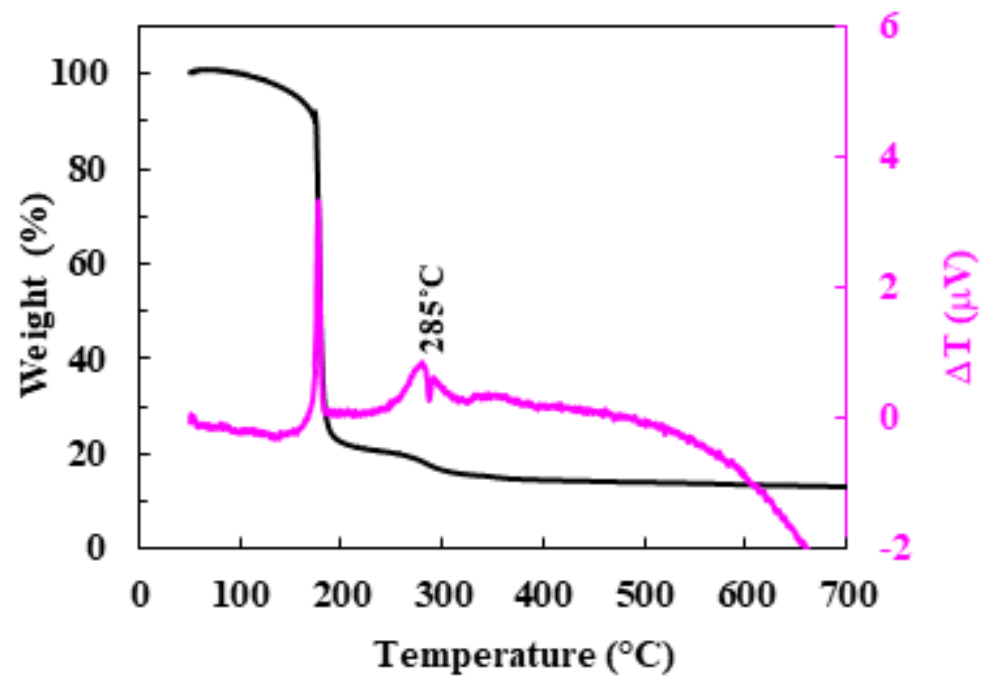

Figure 2

TGA/DTA curves of the dried gel prepared by a mixture of CTAB and glycine fuels at $\varphi=1$.

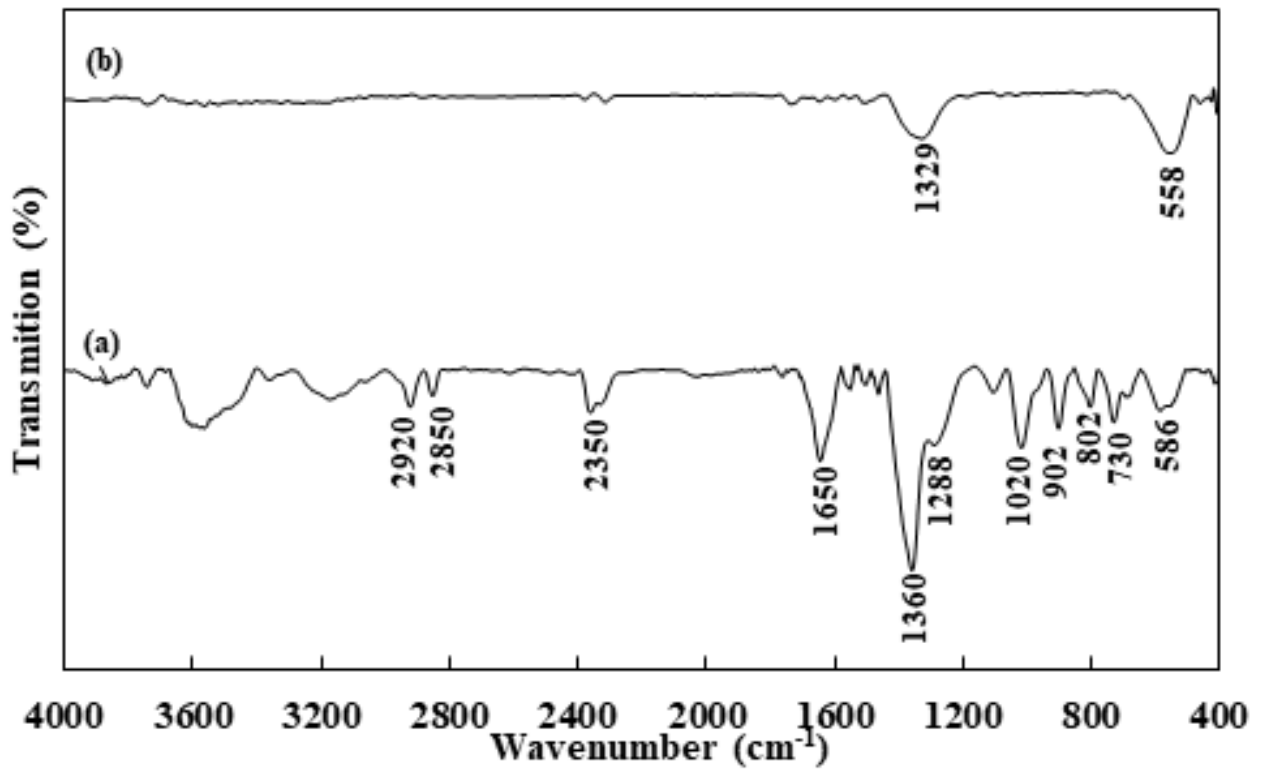

Figure 4

FTIR spectra of (a) dried gel and (b) the as-combusted BFO powders at $\varphi=1$. 


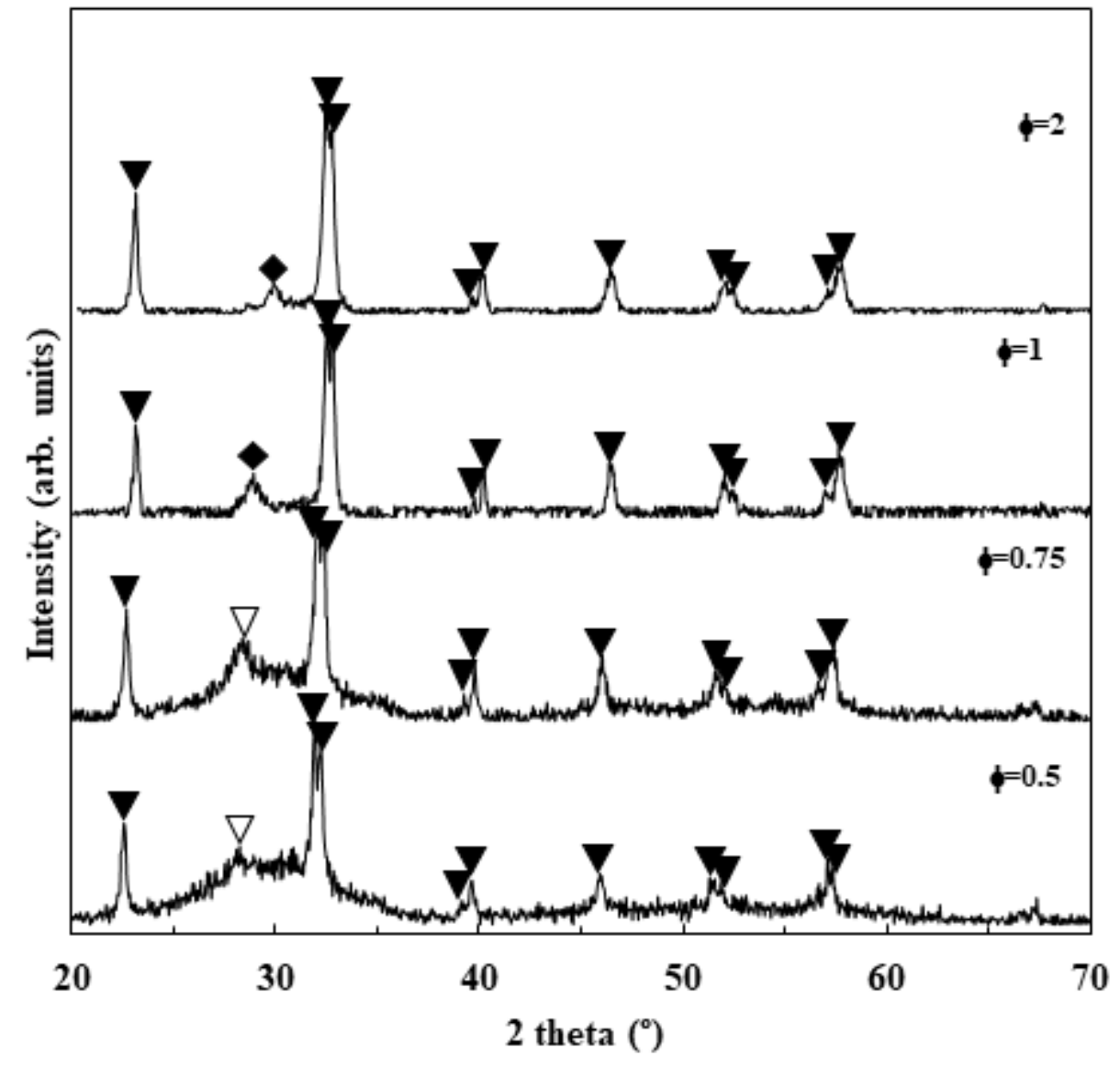

Figure 6

XRD patterns of the as-combusted BFO powders using glycine and CTAB fuel content. ( : BiFeO3, : Bi2Fe409 , : Bi24Fe2039) 


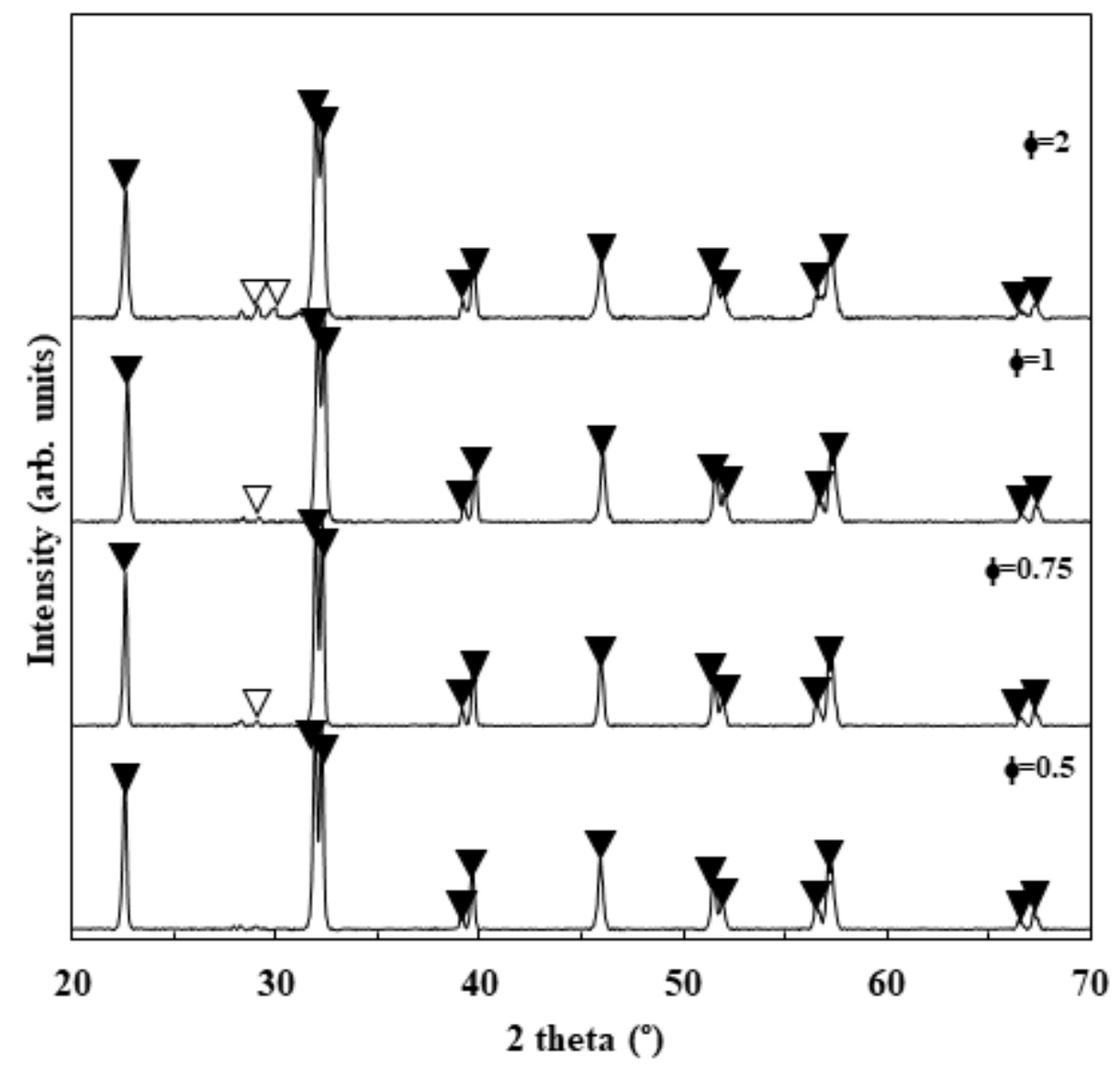

Figure 8

XRD patterns of the as-calcined BFO powders using glycine and CTAB fuel content. (: BiFeO3, : Bi2Fe4O9 ) . 

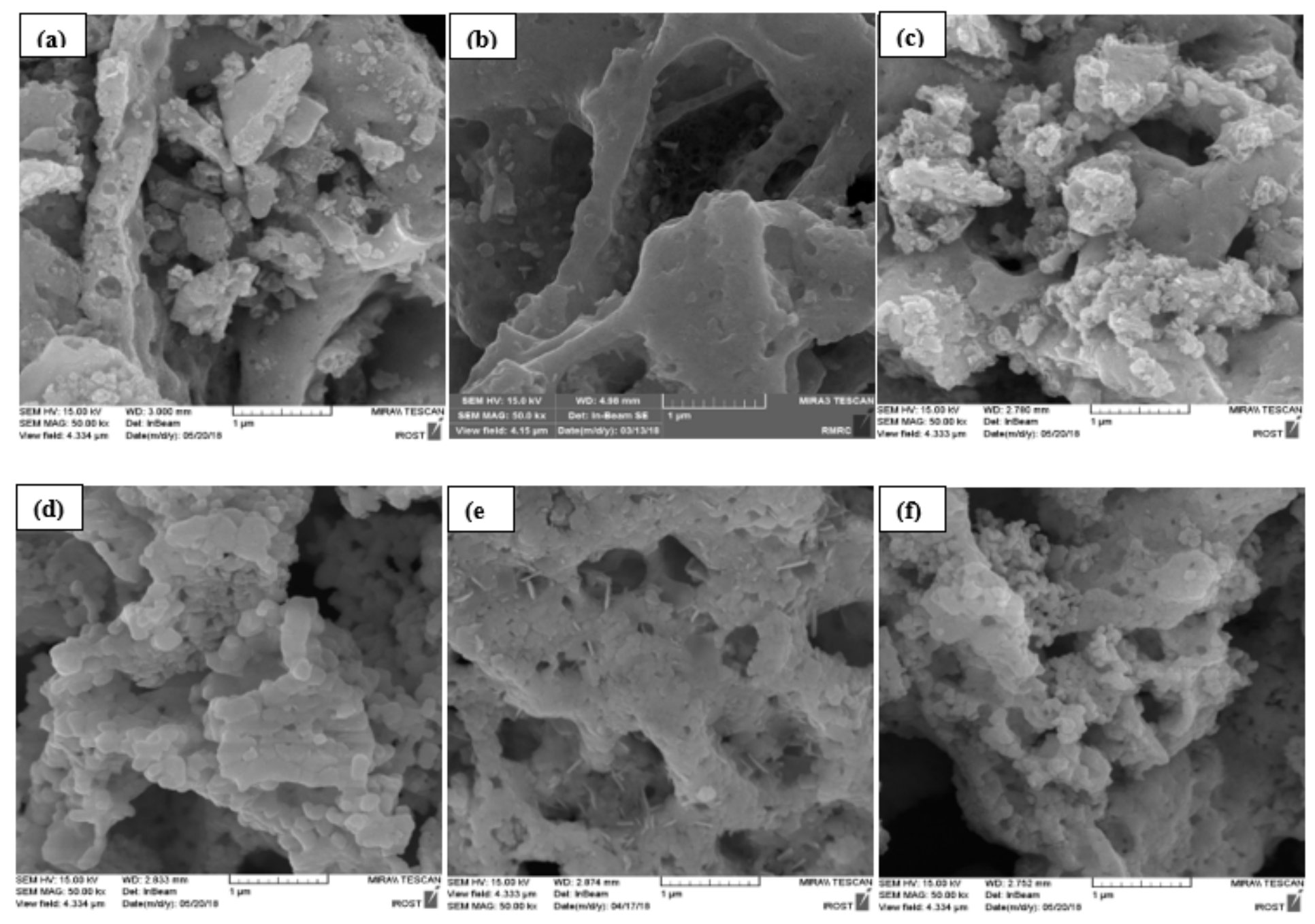

Figure 10

SEM micrographs of the as-combusted BFO powders at (a) $\varphi=0.75$, (b) $\varphi=1$ and (c) $\varphi=2$ and the ascalcined BFO powders at (d) $\varphi=0.75$, (e) $\varphi=1$ and (f) $\varphi=2$.

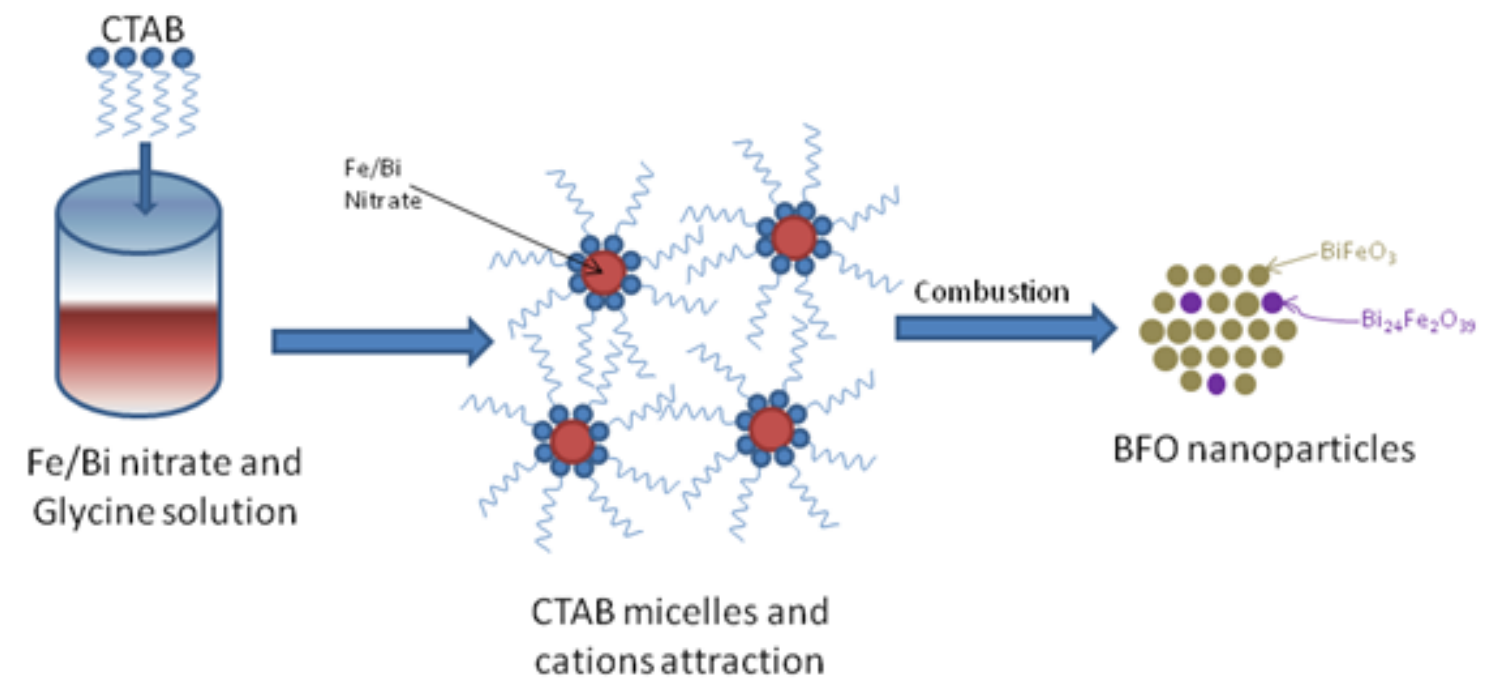


Figure 12

Schematic of BFO nanoparticle synthesis via micells formation at high CTAB content.
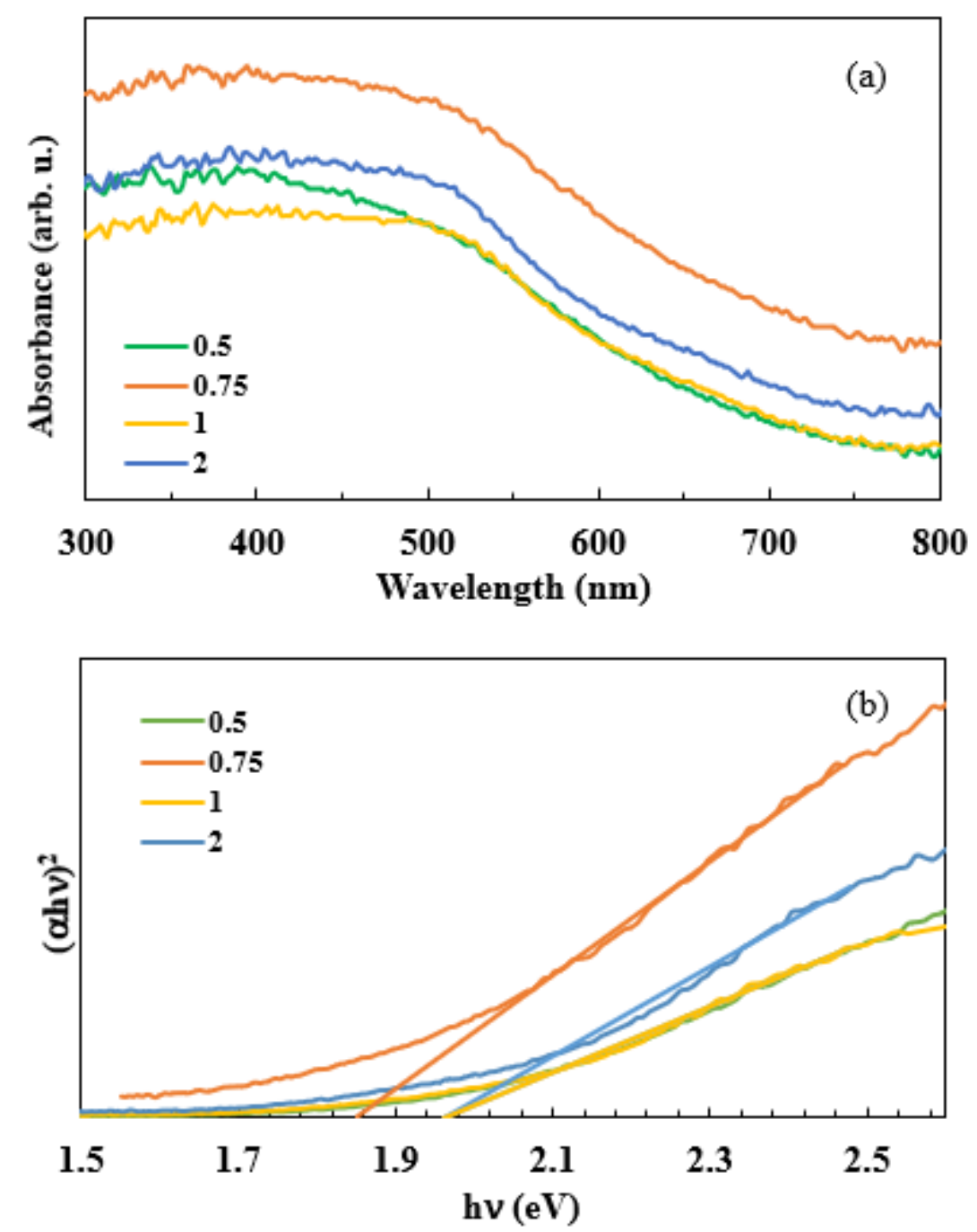

Figure 14

(a) UV-Vis diffuse reflectance spectra and (b) Tauc's plot of the as-combusted BFO powders. 


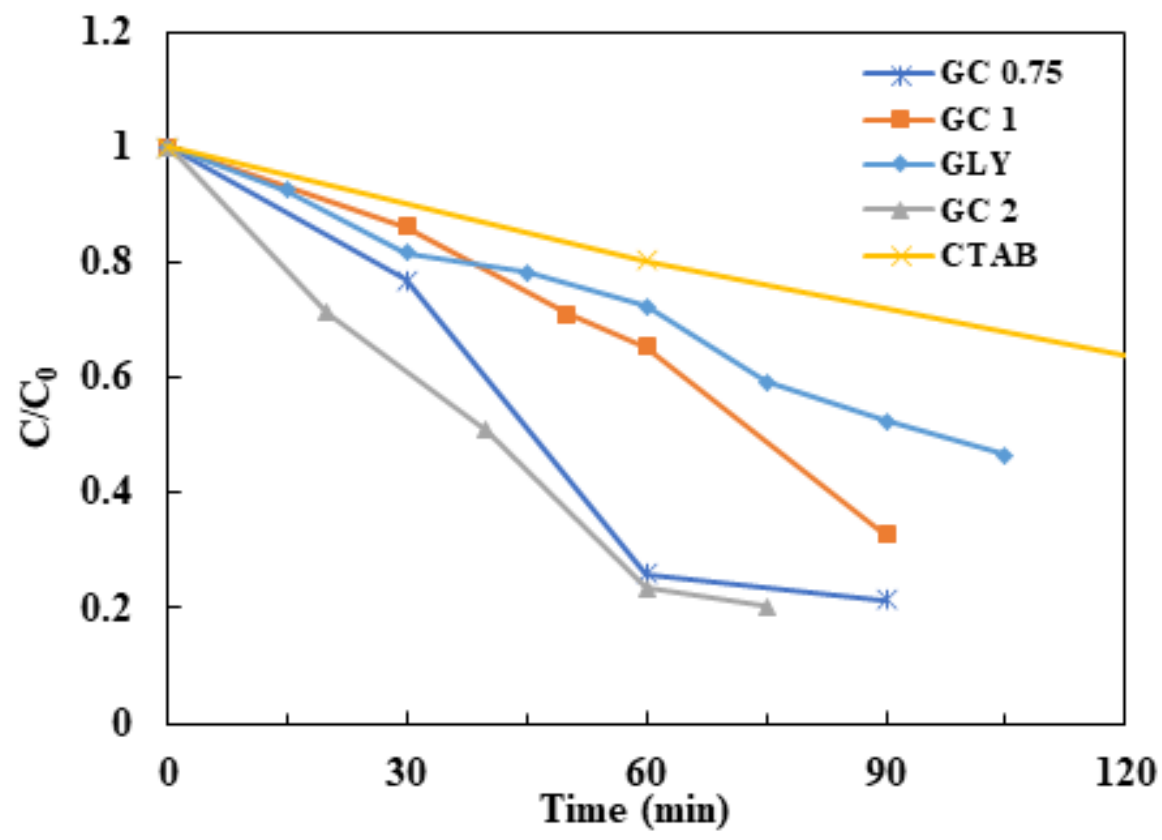

Figure 16

$\mathrm{C} / \mathrm{CO}$ vs. irradiation time in the presence of the BFO powders at different fuel content and type. 